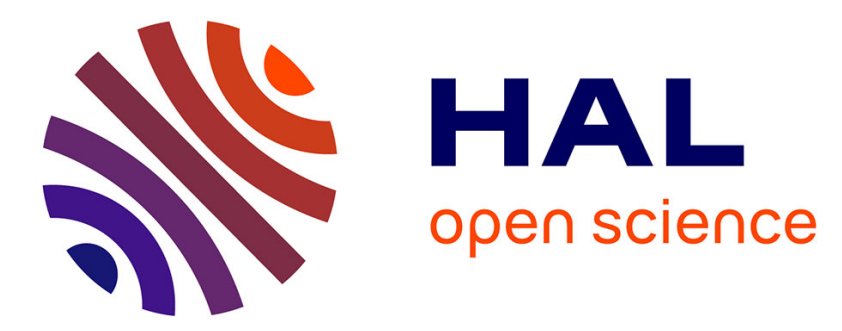

\title{
High energy erbium laser end-pumped by a laser diode bar array coupled to a Nonimaging Optic Concentrator
}

Eric Tanguy, Gilles Feugnet, Jean-Paul Pocholle, R. Blondeau, M.A. Poisson, J.P. Duchemin

\section{- To cite this version:}

Eric Tanguy, Gilles Feugnet, Jean-Paul Pocholle, R. Blondeau, M.A. Poisson, et al.. High energy erbium laser end-pumped by a laser diode bar array coupled to a Nonimaging Optic Concentrator. Optics Communications, 1998, 145, pp.105-108. hal-00934651

\section{HAL Id: hal-00934651 https://hal.science/hal-00934651}

Submitted on 29 Jan 2014

HAL is a multi-disciplinary open access archive for the deposit and dissemination of scientific research documents, whether they are published or not. The documents may come from teaching and research institutions in France or abroad, or from public or private research centers.
L'archive ouverte pluridisciplinaire HAL, est destinée au dépôt et à la diffusion de documents scientifiques de niveau recherche, publiés ou non, émanant des établissements d'enseignement et de recherche français ou étrangers, des laboratoires publics ou privés. 


\title{
High energy erbium laser end-pumped by a laser diode bar array coupled to a Nonimaging Optic Concentrator
}

\author{
E. Tanguy ${ }^{\mathrm{a}}$, G. Feugnet ${ }^{\mathrm{b}}$, J.P. Pocholle ${ }^{\mathrm{b}}$, R. Blondeau ${ }^{\mathrm{b}}$, M.A. Poisson ${ }^{\mathrm{b}}$, \\ J.P. Duchemin ${ }^{b}$ \\ ${ }^{a}$ Faculté des Sciences et des Techniques de Nantes, Groupe de Physique des Solides pour l'Electronique, 2, rue de la Houssinière, BP \\ 92208, Nantes Cedex 03, France \\ ${ }^{\mathrm{b}}$ Laboratoire Central de Recherches, Thomson-C.S.F., Domaine de Corbeville, Orsay Cedex 91404, France
}

\begin{abstract}
A high energy $\mathrm{Er}^{3+}, \mathrm{Yb}^{3+}$ :glass laser end pumped by a laser diode array emitting at $980 \mathrm{~nm}$ coupled to a Nonimaging Optic Concentrator (NOC) is demonstrated. Energy up to $100 \mathrm{~mJ}$ and a $16 \%$ slope efficiency are achieved in a plano-plano laser cavity. The energy transfer coefficient from $\mathrm{Yb}^{3+} \mathrm{to}^{\mathrm{E}}{ }^{3+}$ is estimated by a new method. (C) 1998 Elsevier Science B.V.
\end{abstract}

\section{Introduction}

A high energy compact laser emitting in the $1.5 \mu \mathrm{m}$ eye-safe spectral range will find very promising applications in the fields of telemetry or lidar [1]. Codoped $\mathrm{Er}^{3+}$, $\mathrm{Yb}^{3+}$ phosphate glass [2] end pumped by a laser diode bar array leads to a low-cost, compact micro-laser operating at $1.5 \mu \mathrm{m}$ [3]. A stack of laser diode bar arrays collimated in the fast axis by microcylindrical lenses associated to a lens duct was already used to end-pump a $\mathrm{Nd}^{3+}$ :YLF laser oscillator [4], and our laboratory has already demonstrated the use of a laser diode bar array coupled to a Nonimaging Optic Concentrator (NOC) to increase the efficiency of a $\mathrm{Nd}: \mathrm{YVO}_{4}$ laser [5]. In this paper, we present an Er:Yb:glass laser using such a configuration.

\section{Pump source}

The laser diode bar array used in this experiment was manufactured by THOMSON-CSF Semi-conducteurs Spécifiques and THOMSON-CSF LCR. It consists of a 10 $\mathrm{mm}$ wide bar with about 70 emitters. The threshold current is around $16 \mathrm{~A}$ and the external quantum efficiency is 1.1 W/A. At an operating current of $90 \mathrm{~A}$, we measured $80 \mathrm{~W}$ peak power with a $10 \mathrm{~ms}$ pulse duration and a $2 \mathrm{~Hz}$ repetition rate (see Fig. 1). The bar emission wavelength is centered at $964 \mathrm{~nm}$ with a FWHM spectral width of 12 nm.

The laser diode bar has a $7^{\circ}$ FWHM beam divergence in the slow axis and a $37.5^{\circ} \mathrm{FWHM}$ divergence in the fast axis.

This laser diode bar associated with a Nonimaging Optic Concentrator (NOC) was used to end pump an $\mathrm{Er}^{3+}: \mathrm{Yb}^{3+}$ :glass rod (see Fig. 3). In this configuration a quasi-symmetric high energy source was achieved. The emissive surface of the laser diode bar array, typically 10 $\mathrm{mm} \times \approx 1 \mu \mathrm{m}$, cannot efficiently match to obtain an intracavity $\mathrm{TEM}_{00}$ mode. By using the NOC, we obtain an emissive area of $1.5 \times 1.5 \mathrm{~mm}^{2}$, contributing to increase the overlap between the pump distribution and the intracavity $\mathrm{TEM}_{00}$ mode.

The design of the NOC was described in Ref. [6]. The bar width is reduced to $1.5 \mathrm{~mm}$ and the lens duct thickness is constant and equal to $1.5 \mathrm{~mm}$, so that the energy is concentrated into a square of $1.5 \times 1.5 \mathrm{~mm}^{2}$ cross section. The input face in front of the NOC has a $9.8 \mathrm{~mm}$ radius of curvature. Conforming to the étendue invariance law [7], the HWHM (Half Width at Half Maximum) divergence in 


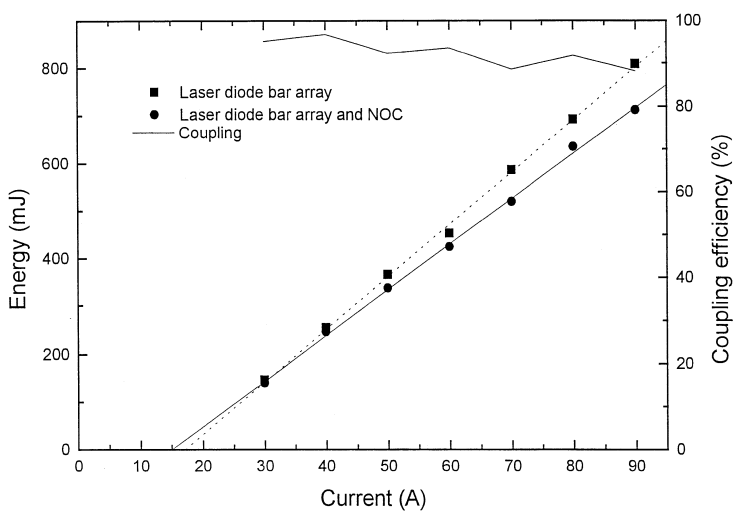

Fig. 1. Input and output energy versus the pump current. Current pulses are $10 \mathrm{~ms}$ long and the repetition rate is $2 \mathrm{~Hz}$.

the slow axis should be $\arcsin \left(11 \sin \left(5^{\circ}\right) / 1.5\right) \approx 35^{\circ}$ while the HWHM divergence in the fast axis plane remains unchanged ( $18^{\circ}$ in our case).

A theoretical coupling efficiency was calculated to be between $87 \%$ (with no anti-reflection coating at the NOC faces) and $92 \%$ (with a perfect anti-reflection coating at the NOC).

A $90 \%$ coupling efficiency was measured (see Fig. 1). With this device a pump source delivering about $700 \mathrm{~mJ}$ concentrated into a $1.5 \times 1.5 \mathrm{~mm}$ with a $70^{\circ} \times 36^{\circ} \mathrm{FWHM}$ divergence in the slow and in the fast axis respectively.

A ray tracing plot for this source is given in Fig. 2.

\section{Laser experiment}

The laser cavity is shown in Fig. 3. The $\mathrm{Er}^{3+}: \mathrm{Yb}^{3+}$ :glass is a commercially available $\mathrm{Er}^{3+}, \mathrm{Yb}^{3+}$

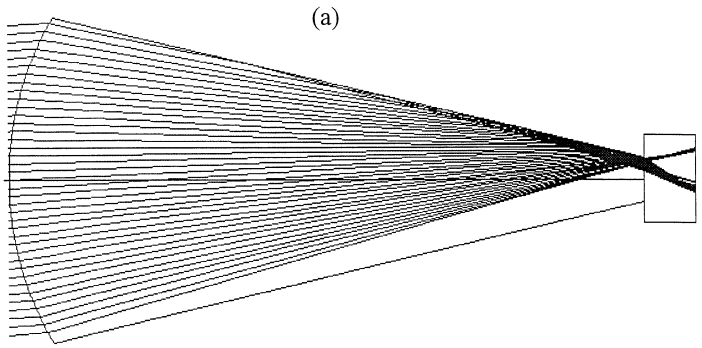

(b)

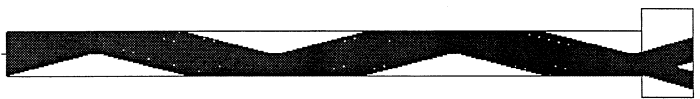

Fig. 2. Ray-tracing plot of the lens duct for rays emitted at an angle of $3.5^{\circ}$ in the array slow-axis (a) and at an angle of $18.75^{\circ}$ in the array fast-axis (b).

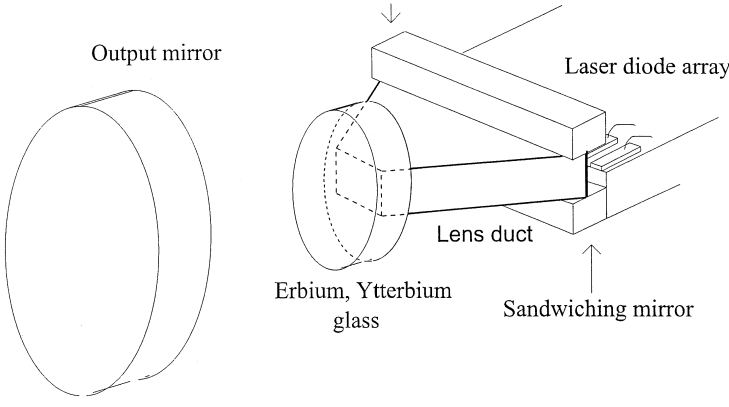

Fig. 3. Laser cavity layout.

codoped glass provided by Kigre Inc. According to Kigre Inc., this new glass presents better thermal performance than the previous one [8], which makes it very attractive for use with high pump powers. The glass disc is $10 \mathrm{~mm}$ in diameter and $2 \mathrm{~mm}$ long. The NOC is in contact with the input face of the rod. One face of the rod is high-reflection coated at $1.54 \mu \mathrm{m}$ and presented a good transmission at $980 \mathrm{~nm}(>90 \%)$; the other face is anti-reflection coated at $1.54 \mu \mathrm{m}$. The output mirror reflection is $99 \%$ at $1.54 \mu \mathrm{m}$. The total cavity length is around $10 \mathrm{~mm}$. The laser rod is uncooled.

Fig. 4 depicts the output energy of the free-running mode versus the pump energy incident upon the laser glass.

The transverse mode of the laser is similar to the pump mode, so we can assume that the plano-plano cavity is more stabilized by gain guiding than thermal lensing. We have not performed thermal lensing measurement but we do not observe thermal degradation of the slope efficiency as the pump power is increased (see Fig. 4).

From experimental data, a $105 \mathrm{~mJ}$ pump energy threshold and a slope efficiency of $16 \%$ were measured.

If the pulse shape due to relaxation oscillation is ne-

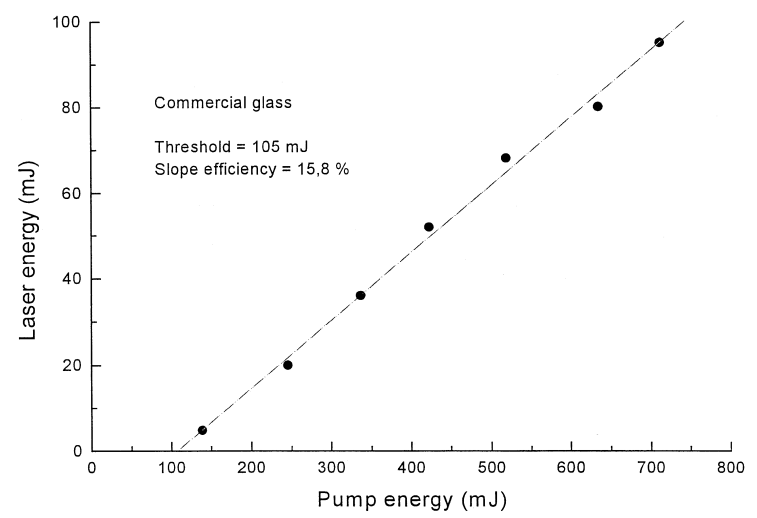

Fig. 4. Output energy versus pump energy for $10 \mathrm{~ms}$ long pulses and $2 \mathrm{~Hz}$ repetition rate. 


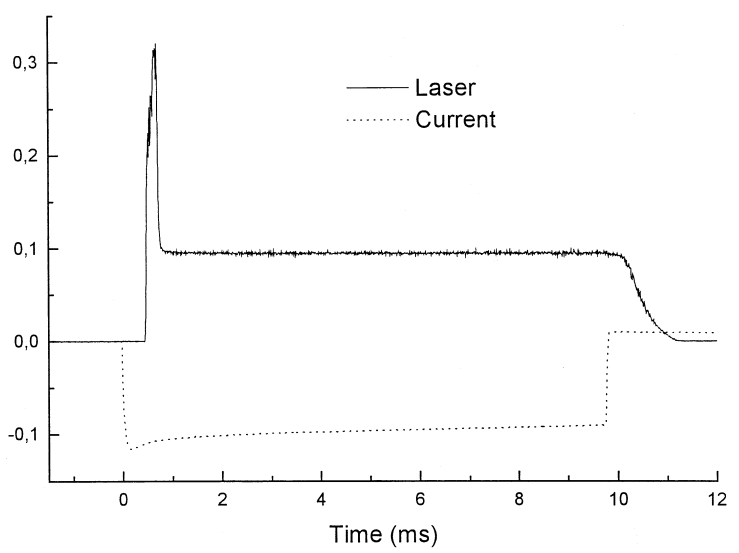

Fig. 5. Laser pulse and current pulse versus time.

glected and if the laser pulse is almost rectangular, then the peak power was $10 \mathrm{~W}$.

The repetition rate is limited to $2 \mathrm{~Hz}$ by thermal effects in the diode bar. With a $10 \mathrm{~ms}$ pulse duration increasing the repetition rate leads to a drastic reduction of the emitted power.

The temporal profile of the laser pulse is shown in Fig. 5.

The laser pulse begins $500 \mu \mathrm{s}$ after the current pulse. This delay time is the result of:

- the time to excite $\mathrm{Yb}^{3+}$ ions by the pump;

- the energy transfer from $\mathrm{Yb}^{3+}$ to $\mathrm{Er}^{3+}$ ions;

- the laser pulse build-up.

\section{Estimation of the energy transfer coefficient from $\mathbf{Y b}^{3+}$ to $\mathbf{E r}^{3+}$ ions}

The energy transfer coefficient from $\mathrm{Yb}^{3+}$ to $\mathrm{Er}^{3+}$ ions is an important parameter to model the laser performance. This parameter was already investigated in phosphate-doped glasses and estimated between $2 \times 10^{-22}$ $\mathrm{m}^{3} \mathrm{~s}^{-1}$ and $5 \times 10^{-22} \mathrm{~m}^{3} \mathrm{~s}^{-1}$ [9-11] but not in this material. It seems to be possible to evaluate it from the decay time of the laser emission and from the simple rate equations.

The beginning of the pulse is characterized by oscillations due to the $\mathrm{Yb}^{3+}, \mathrm{Er}^{3+}$ energy transfer and laser relaxation followed by a pseudo-steady state that begins at about $1 \mathrm{~ms}$. At $10 \mathrm{~ms}$, the laser output decreases at the same speed as the upper level population of the ytterbium decrease.

The population parameters of each level are given in Fig. 6.

Assuming that the $\mathrm{Er}^{3+}{ }^{4} \mathrm{I}_{11 / 2}$ lifetime is very short ( $\cong 100 \mu \mathrm{s}$ ), we have neglected the back energy transfer from $\mathrm{Er}^{3+}$ to $\mathrm{Yb}^{3+}$.
To describe these phenomena, we can write the rate equations governing the population of each level:

$$
\begin{aligned}
\frac{\mathrm{d} N_{3}^{\prime}}{\mathrm{d} t} & =\sigma_{\mathrm{p}} N^{\prime} \Phi_{\mathrm{p}}(\boldsymbol{r}, t)-k N_{3}^{\prime} N_{1}-\gamma_{\mathrm{yb}} N_{3}^{\prime}, \\
\frac{\mathrm{d} N_{3}}{\mathrm{~d} t} & =k N_{3}^{\prime} N_{1}-\gamma_{31} N_{3}-\gamma_{32} N_{3}, \\
\frac{\mathrm{d} N_{2}}{\mathrm{~d} t} & =\gamma_{32} N_{3}-\gamma_{21} N_{2}-\left(N_{2}-N_{1}\right) \sigma_{\mathrm{e}} \Phi_{1}(\boldsymbol{r}, t),
\end{aligned}
$$

$\sigma_{\mathrm{p}} N_{1}^{\prime} \Phi_{\mathrm{p}}(\boldsymbol{r}, t)$ is the pump term, $k N_{3}^{\prime} N_{1}$ is the energy transferred from $\mathrm{Yb}^{3+}$ to $\mathrm{Er}^{3+}, \gamma_{\mathrm{yb}} N_{3}^{\prime}$ is the $\mathrm{Yb}^{3+}$ decay, $\gamma_{i j} N_{1}$ is the decay from level $i$ to level $j$, and $\left(N_{2}-\right.$ $\left.N_{1}\right) \sigma_{\mathrm{e}} \Phi_{1}(\boldsymbol{r}, t)$ is the stimulated emission. $\sigma_{\mathrm{p}}$ is the absorption cross section, $\sigma_{\mathrm{e}}$ is the emission cross section $(8 \times$ $\left.10^{-25} \mathrm{~m}^{2}\right), \gamma_{\mathrm{yb}}$ is the $\mathrm{Yb}^{3+}$ decay rate $\left(10^{3} \mathrm{~s}^{-1}\right), \gamma_{i j}$ is the decay rate from level $j$ to level $i, k$ is the energy transfer coefficient from $\mathrm{Yb}^{3+}$ to $\mathrm{Er}^{3+}, \Phi_{\mathrm{p}}(r, t)$ is the pump flux, and $\Phi_{1}(r, t)$ is the laser flux.

After the pseudo-steady state, the laser output decreases. The erbium upper laser level stays at the same population as the threshold one. The laser power decreases at the same rate as the ytterbium upper level,

$$
\begin{aligned}
\frac{\mathrm{d} N_{3}^{\prime}}{\mathrm{d} t} & =\sigma_{\mathrm{p}} N_{1}^{\prime} \Phi_{\mathrm{p}}(\boldsymbol{r}, t)-k N_{3}^{\prime} N_{1}-\gamma_{\mathrm{yb}} N_{3}^{\prime} \\
& =-k N_{3}^{\prime}\left(N_{\mathrm{er}}-N_{2}\right)-\gamma_{\mathrm{yb}} N_{3}^{\prime},
\end{aligned}
$$

with $N_{\text {er }}$ the erbium concentration $\left(1.4 \times 10^{25} \mathrm{~m}^{-3}\right.$ in our case).

The solution is a decreasing exponential:

$N_{3}^{\prime}(t)=A \exp \left\{-\left[k N_{\mathrm{er}}\left(1-n_{2}\right)+\gamma_{\mathrm{yb}}\right] t\right\}$,

with a time constant

$1 / \tau=k N_{\mathrm{er}}\left(1-n_{2 \mathrm{t}}\right) \gamma_{\mathrm{yb}}$ and $0<n_{2 \mathrm{t}}<1$.

If we can estimate $n_{2 t}$, we are able to estimate the time energy transfer coefficient $k$. If the cavity losses (except output coupling) can be neglected, the internal gain can be estimated as more than $1 \%$. The round trip gain is

$G=1-\exp \left[2 \sigma_{\mathrm{e}} N_{\mathrm{er}}\left(2 n_{2}-1\right) l\right]$,

where $l$ is the laser rod length. $G>1 \%$ leads to $n_{2 \mathrm{t}}>0.61$.

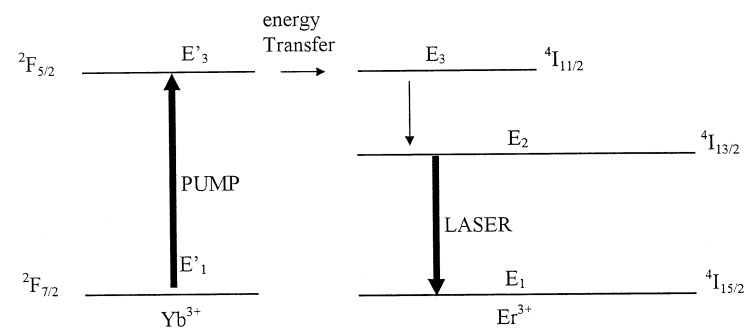

Fig. 6. Energy diagram of the energy transfer between the $\mathrm{Yb}$ and Er ions [1]. 
According to Fig. 5, we measured $\tau \approx 450 \mu$ s. Thus we find that $k$ is greater than $2.24 \times 10^{-22} \mathrm{~m}^{3} \mathrm{~s}^{-1}$. In this three level system, we can reasonably conclude that $n_{2 \mathrm{t}}<$ 0.85 . Finally we obtain $2.24 \times 10^{-22} \mathrm{~m}^{3} \mathrm{~s}^{-1}<k<5.8 \times$ $10^{-22} \mathrm{~m}^{3} \mathrm{~s}^{-1}$. These results are in good agreement with the results mentioned in Refs. [9-11].

\section{Conclusion}

We have demonstrated a high energy laser emitting at $1.54 \mu \mathrm{m}$. It was end pumped by a laser diode bar array associated with a Nonimaging Optic Concentrator and delivered up to $100 \mathrm{~mJ}$ in a $10 \mathrm{~ms}$ long pulse at a $2 \mathrm{~Hz}$ repetition rate. We have estimated by a new method the energy transfer coefficient from $\mathrm{Yb}^{3+}$ to $\mathrm{Er}^{3+}$ between $2.24 \times 10^{-22} \mathrm{~m}^{3} \mathrm{~s}^{-1}$ and $5.8 \times 10^{-22} \mathrm{~m}^{3} \mathrm{~s}^{-1}$.

\section{References}

[1] V.P. Gapontsev, S.M. Matitsin, A.A. Isineer, V.B. Kravchenko, Optics Laser Technol. 14 (1982) 189.

[2] Shibin Jiang et al., Laser and thermal performance of a new erbium doped phosphate laser glass, KIGRE Inc. technical paper.

[3] P. Laporta, S. Taccheo, S. Longhi, O. Svelto, Optics Lett. 18 (1993) 1232.

[4] R. Beach, P. Reichert, W. Benett, B. Freitas, S. Mitchell, A. Velsko, J. Davin, R. Solarz, Optics Lett. 18 (1993) 1326.

[5] G. Feugnet, C. Bussac, M. Schwarz, C. Larat, J.P. Pocholle, Optics Lett. 20 (1995) 157.

[6] G. Feugnet, C. Bussac, M. Schwarz, C. Larat, J.P. Pocholle, High efficiency $\mathrm{TEM}_{00} \quad \mathrm{Nd}: \mathrm{YVO}_{4}$ laser longitudinally pumped by a high power laser diode array, Proc. SPIE, Nonimaging Optics III: Maximum Efficiency Light Transfer, 1995.

[7] T. Welford, R. Winston, High Collection Nonimaging Optics, Academic Press, 1989, p. 53.

[8] S. Jiang, J. Myers, D. Rhonehouse, M. Myers, R. Belford, S. Hamlin, Laser and thermal performance of a new erbium doped phosphate laser glass, SPIE Vol. 2138, Longer-Wavelength Lasers and Applications, 1994.

[9] V.P. Gapontsev et al., Optics Laser Technol. 14 (1982) 189.

[10] V.P. Gapontsev, N.S. Platonov, in: Dynamical Processes in Disordered Systems, Ed. W.M. Yen, Material Science Forum 51, Aedermannsdorf, Switzerland, 1989.

[11] J. Nilson, P. Scheer, B. Jaskorzynska, IEEE Photon. Technol. Lett. 6 (1994) 383. 